\title{
Identification of two linear plasmids in the actinomycete Planobispora rosea
}

\author{
Simona Polo, ${ }^{1} \dagger$ Oscar Guerini, ${ }^{1}$ Margherita Sosio ${ }^{2}$ and Gianni Dehò
}

\begin{abstract}
Author for correspondence: Gianni Dehò. Tel: +3922660 5217. Fax: +3922664551.
\end{abstract}
e-mail:deho@imiucca.csi.unimi.it

\footnotetext{
1 Dipartimento di Genetica e di Biologia dei Microrganismi, Università degli Studi di Milano, Via Celoria 26, 20133 Milano, Italy

2 Biosearch Italia, Gerenzano, Italy
}

\begin{abstract}
Two linear plasmids (PPR1, $27.5 \mathrm{~kb}$, and pPR2, $16 \mathrm{~kb}$ ) were identified in Planobispora rosea, an actinomycete that produces the antibiotic GE2270, an inhibitor of the elongation factor Tu. Strains lacking both plasmids still produce and are resistant to GE2270. The two plasmids share an internal region of high similarity, but no cross-hybridization was detected between their telomeric regions or between plasmid and chromosomal DNA. The $5^{\prime}$ ends of the plasmids appear to be linked to terminal proteins. The telomeric regions of PPR2 were cloned after 3'-end homopolymer tailing and PCR amplification. The approximately $650 \mathrm{nt}$ telomeric DNA sequences of PPR2 are repeated in inverted orientation and are rich in direct and inverted repeats; the $350 \mathrm{bp}$ terminal region is less $\mathbf{G}+\mathbf{C}$-rich than the rest of the plasmid. The structural organization of these plasmids appears to be similar to Streptomyces linear replicons.
\end{abstract}

Keywords: telomeres, terminal protein, Actinomycetales, replication, inverted repeats

\section{INTRODUCTION}

Reports of linear DNA molecules in prokaryotes have become increasingly frequent and linear bacteriophages, plasmids and bacterial chromosomes no longer appear an exception to the paradigm of the circular bacterial replicon (for reviews see Hinnebusch \& Tilly, 1993; Chen, 1996).

Numerous linear plasmids have been found in several Streptomyces species (Kinashi et al., 1987; Sakaguchi, 1990), and occasionally in other Actinomycetales (Crespi et al., 1992; Kalkus et al., 1990, 1993). These extrachromosomal replicons range in size from 12 to more than $600 \mathrm{~kb}$ (Sakaguchi, 1990; Kinashi et al., 1987), and more than one plasmid may coexist in the same host. Interestingly, the Streptomyces chromosome is also linear (Lin et al., 1993; Chen et al., 1993; Lezhava et al., 1995; Leblond et al., 1996), although circular forms have been described for some deletion mutants in Streptomyces lividans (Lin et al., 1993).

All the Streptomyces linear plasmids characterized thus far share structural features: the telomeric regions are long inverted repeats from 0.6 to $81 \mathrm{~kb}$ in length containing direct and inverted repeated sequences

†Present address: Human Virology Unit, DIBIT, San Raffaele Scientific Institute, Milano, Italy.

The GenBank accession numbers for the sequences reported in this paper are AF041863, AF041864 and AF041865.
(Hirochika et al., 1984; Kinashi et al., 1991; Wu \& Roy, 1993). In most cases analysed, a terminal protein is covalently linked to the $5^{\prime}$ ends of the DNA molecule. In a few instances the presence of such plasmids has been associated with the production of antibiotics (Kinashi et al., 1987; Davies, 1994).

Two main types of telomeric organization have been described in bacterial linear replicons: (i) covalently closed palindromic hairpin loops, as exemplified by the plasmid prophage form of coliphage N15 (Malinin et al., 1992; Svarchevsky \& Rybchin, 1984 ; Łobocka et al., 1996) and the linear plasmids and chromosome of Borrelia (Hinnebusch \& Barbour, 1991; Barbour et al., 1996; Casjens et al., 1997; Fraser et al., 1997); and (ii) terminal inverted repeats with $5^{\prime}$ ends covalently linked to a terminal protein, as exemplified by the well characterized Bacillus subtilis phage $\Phi 29$ (reviewed by Salas, 1991) and by several Streptomyces plasmids (Sakaguchi, 1990). The mechanism of replication of the former type of linear replicon has not yet been detailed, whereas two different replication strategies have been described in the latter type: (i) $\Phi 29$ replication starts at both ends, using the terminal protein as the primer, and proceeds throughout the whole DNA molecule; (ii) several streptomycete plasmids and linear chromosomes, as well as the linear plasmids of Borrelia, appear to replicate bidirectionally from a unique internal origin; in such instances, telomere-promoted replication appears to be confined to the terminal regions of the 
linear molecule (Casjens \& Huang, 1993; Chang \& Cohen, 1994; Chang et al., 1996).

Planobispora rosea is an actinomycete that produces the antibiotic GE2270, a thiazolyl peptide inhibitor of the translation elongation factor Tu (Goodfellow, 1992; Selva et al., 1991; Anborgh \& Parmeggiani, 1991; Tavecchia et al., 1995). Here, we report the identification and preliminary characterization of two linear plasmids (pPR 1, 27.5 kb long, and pPR2, $16 \mathrm{~kb}$ ) from this strain. They were found to share structural features with other Streptomyces linear replicons.

\section{METHODS}

Bacterial strains and plasmids. $P$. rosea (ATCC 53733) strains Pbr 1435, Pbr 1438, Pbr 1439, Pbr 1440, Pbr 1441 and Pbr 1832 were obtained from the Biosearch Italia (formerly Lepetit Research Center) strain collection and were cultivated as described by Selva et al. (1991). GE2270 production was measured as described by Selva et al. (1991). Plasmid pGEM$3 Z$ (Promega) was used for cloning pPR 1 and pPR 2 restriction fragments. Escherichia coli DH5 $\alpha$ (Hanahan, 1983) and JM109 (Yanisch-Perron et al., 1985) were used as recipients in transformations with the recombinant plasmids.

DNA preparation. Total DNA of $P$. rosea was prepared from $5 \mathrm{~g}$ wet-packed mycelia according to Fishman \& Hershberger (1983) with some modifications. In brief, the mycelium resuspended in $10 \mathrm{mM}$ Tris, $0.125 \mathrm{M}$ EDTA, $12.5 \%(\mathrm{w} / \mathrm{v})$ sucrose was treated with lysozyme $\left(10 \mathrm{mg} \mathrm{ml}^{-1}\right)$ for $15 \mathrm{~min}$ at room temperature. Proteinase $\mathrm{K}$ was added to a final concentration of $50-150 \mu \mathrm{g} \mathrm{ml}^{-1}$ and the lysed suspension was incubated at $65^{\circ} \mathrm{C}$ for $1 \mathrm{~h}$ before precipitation with $0.5 \mathrm{M}$ $\mathrm{NaCl}$ for $2 \mathrm{~h}$ on ice. After centrifugation at $42000 \mathrm{~g}$, the DNA in the supernatant was precipitated with 2-propanol and pelleted by centrifugation.

Linear plasmid DNA was purified from total $P$. rosea DNA by $10-30 \%$ sucrose $/ 1 \mathrm{M} \mathrm{NaCl}$ gradient centrifugation in a Beckman SW40 ultracentrifuge rotor. About $50-150 \mathrm{mg}$ total DNA per $12 \mathrm{ml}$ sucrose gradient was centrifuged for $10 \mathrm{~h}$ at 36000 r.p.m. at $18{ }^{\circ} \mathrm{C}$, collected in $0.7 \mathrm{ml}$ fractions, precipitated with ethanol and pelleted by centrifugation. The dried pellet was dissolved in Tris/EDTA pH 7.2 and analysed by electrophoresis in agarose gels. The fractions that contained predominantly plasmid DNA were pooled. Alternatively, pPR1 and pPR2 DNA was purified from chromosomal DNA by inverted-field agarose gel electrophoresis with a Bio-Rad Pulsewave 750 apparatus and electroeluted from the gel. Ethidium bromide/ $\mathrm{CsCl}$ equilibrium gradient centrifugation was performed as described by Maniatis et al. (1982).

DNA manipulations. Poly $(\mathrm{dT})$ or poly $(\mathrm{dA})$ tailing of DNA fragments was performed using calf thymus terminal transferase (Boehringer) under the conditions suggested by the manufacturer. The tailed DNA was then copied for 10 cycles $\left(1 \mathrm{~min}, 95^{\circ} \mathrm{C} ; 1 \mathrm{~min}, 53{ }^{\circ} \mathrm{C} ; 1 \mathrm{~min}, 72^{\circ} \mathrm{C}\right.$ ) with $\mathrm{Taq}$ DNA polymerase (Promega) and PCR-amplified for 30 cycles ( $1 \mathrm{~min}$, $\left.95^{\circ} \mathrm{C} ; 1 \mathrm{~min}, 45^{\circ} \mathrm{C} ; 1 \mathrm{~min}, 72^{\circ} \mathrm{C}\right)$ using either poly $(\mathrm{dA})_{35}$ or poly $(\mathrm{dT})_{35}$ and the oligonucleotide AGAATGGCCACCATAGAAATCCGAT (named PLANEND, from base 336 to 312 on the complementary strand of pPR2 left end; see Fig. 4) as primers.

Southern blot hybridization was performed as described by Maniatis et al. (1982) on Hybond-N (Amersham) nylon membranes. ${ }^{32} \mathrm{P}$-labelled $\mathrm{pPR} 1$ and $\mathrm{pPR} 2 \mathrm{DNA}$ probes were prepared by random primer extension with the Prime-a-Gene labelling kit (Promega).

DNA sequencing and sequence analysis. pPR 2 restriction fragments cloned in pGEM3-Z were sequenced by the method of Sanger et al. (1977) using synthetic oligodeoxynucleotides that primed replication either within the vector plasmid sequence or in previously sequenced pPR2 regions. Sequences were analysed with the GCG software package (Devereux et al., 1984). The GenBank accession numbers for the sequenced regions of pPR2 are AF041863, AF041864 and AF041865 for the internal sequence spanning the region of homology with pPR1, the left telomeric region and the right telomeric region, respectively.

\section{RESULTS AND DISCUSSION}

\section{Identification and characterization of PPR1 and PPR2}

Six strains of $P$. rosea from the Lepetit strain collection were examined for the presence of extrachromosomal elements. When the total bacterial DNA was extracted by procedures in which proteinase $\mathrm{K}$ treatment was performed prior to phenol extraction (either according to Fishman \& Hershberger, 1983 or Hintermann et al., 1981), and fractionated by either standard or invertedfield agarose gel electrophoresis, two discrete bands (see Fig. 3), in addition to the chromosomal DNA, could be detected in strain Pbr 1435 and Pbr 1832, but not in the other strains. The slow- and the fast-migrating bands, named pPR1 and pPR2, respectively, could not be detected when the DNA was obtained by procedures in which phenol extraction was performed prior to proteinase $\mathrm{K}$ treatment. This suggested that the plasmid DNA was tightly associated with proteins and was thus lost in the organic phase.

Ethidium bromide/ $\mathrm{CsCl}$ equilibrium gradient centrifugation of Pbr 1435 DNA indicated that both pPR1 and pPR2 had the same buoyant density as chromosomal DNA: by agarose gel electrophoresis of the gradient fractions, plasmid DNA was detected only in the fractions containing chromosomal DNA (data not shown). This suggested that pPR 1 and $\mathrm{pPR} 2$ could be linear DNA molecules.

We purified the pPR1 and pPR2 DNA either by sucrose gradient centrifugation or by preparative inverted-field agarose gel electrophoresis and performed a restriction analysis of the two plasmids (Fig. 1). These experiments provided conclusive evidence that the plasmids were linear since: (i) none of the 13 enzymes used produced a single fragment that migrated more slowly than the undigested plasmid, as expected for a single cut of a CCC DNA molecule; (ii) the sum of the $M_{\mathrm{r}}$ of the fragments obtained by each of several digestions was approximately equal to the $M_{r}$ of the undigested plasmid; (iii) the number of fragments obtained by digestion with two restriction enzymes was equal to the sum of the number of fragments obtained by the two single digestions minus one, which is diagnostic of a linear molecule. In these experiments the size of pPR1 and pPR2 was estimated to be 27.5 and $16 \mathrm{kbp}$, respectively. 
pPR1

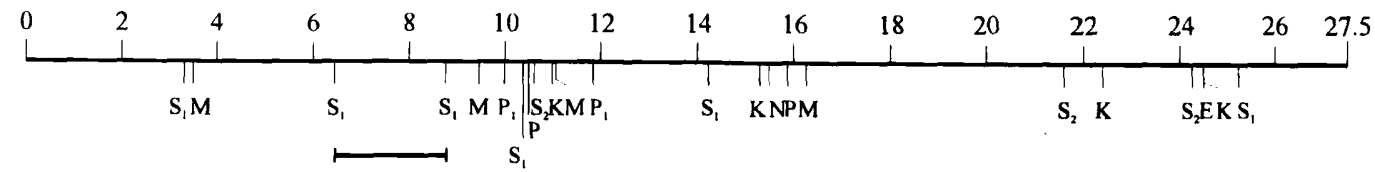

PPR2

\begin{tabular}{|c|c|c|c|c|c|c|c|c|c|}
\hline 0 & & 2 & 4 & 6 & 8 & 10 & 12 & 14 & 16 \\
\hline ! & $T$ & $T T$ & $T$ & $7 \pi$ & $7 \pi$ & $\Pi \pi$ & 1 & $\pi$ & $T$ \\
\hline $\mathrm{E}$ & $\mathrm{N}$ & S S & $\mathrm{N}$ & EAS & $\mathrm{B}_{1} \mathrm{MAKS}$ & KEA & K S & $S_{1} S N S_{1} B$ & E \\
\hline
\end{tabular}

Fig. 1. Restriction maps of pPR1 and pPR2. The maps were established in part by restriction analysis of purified pPR1 or PPR2 DNA and in part by Southern blot analysis of total $P$. rosea DNA digests using ${ }^{32}$ P-labelled pPR1 or PPR2 DNA as probes. Ambiguities were resolved by restriction analysis of cloned fragments and by inspection of sequenced regions. $A$, ApaLI; B, BgllI; B, BamH1; E, EcoRl; K, Kpnl; M, Mlul; N, Nhel; P, Pvull; P, Pstl; S, Sphl; S, Sacl; S , Sall. Xhol did not cut either plasmid. To confirm plasmid linearity, pPR1 was double-digested with Nhel/Mlul and Sall/Pstl, and pPR2 with $B g / l / B a m H I, B g / l / M / u l$ and Nhel/M/ul. Bars indicate the regions of homology between the two plasmids; black rectangles indicate the sequenced regions; arrows indicate the terminal inverted repeats at the PPR2 ends.

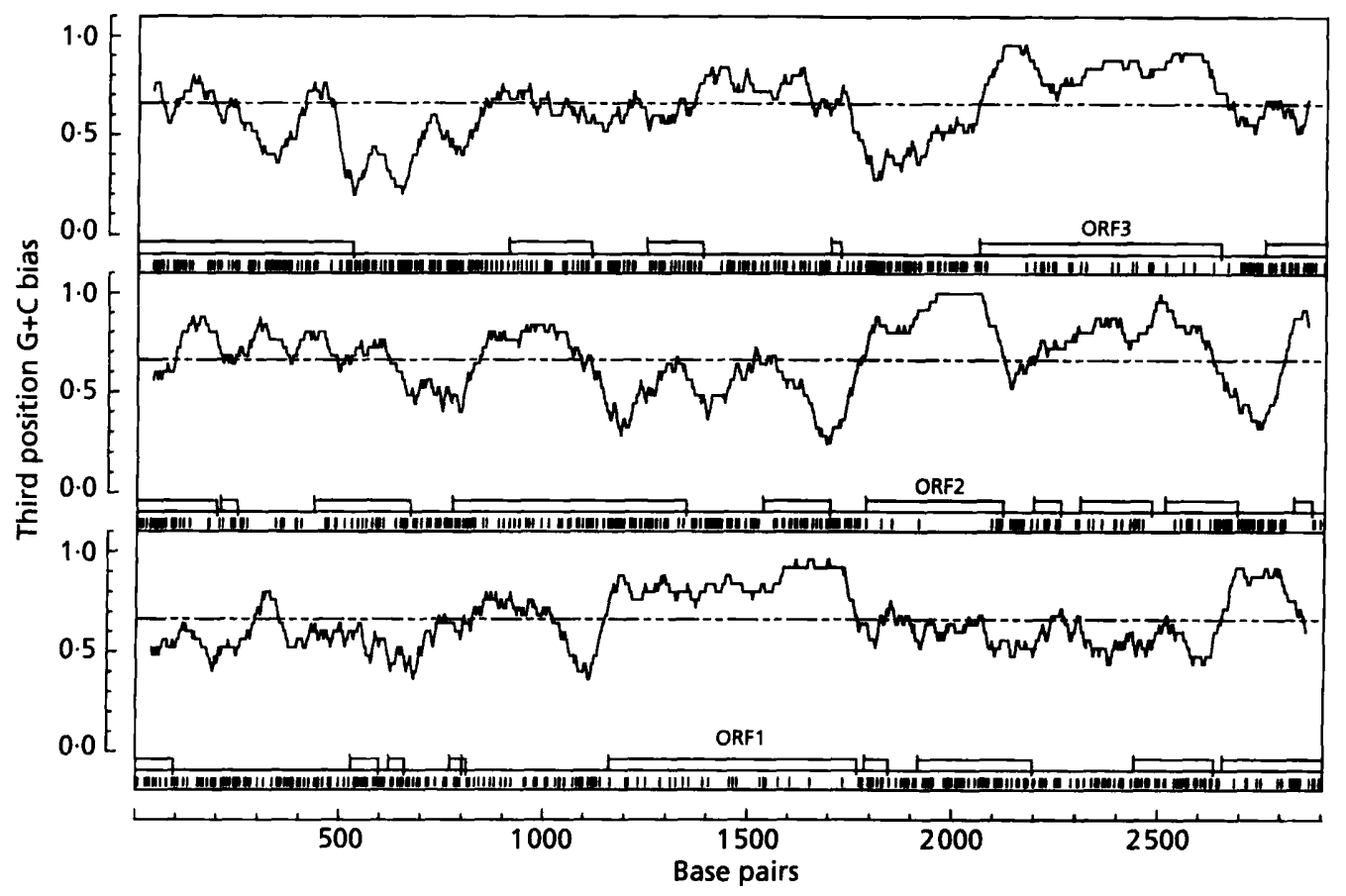

Fig. 2. Identification of potential protein encoding sequences in the homologous region of pPR2. The pPR2 sequence encompassing the region of homology between PPR2 and PPR1 was examined using the CODONPREFERENCE algorithm of the Wisconsin package, with the codon preference table Sererme2 (GenBank). In the plots, which report the results for each reading frame, the straight broken line shows the mean $G+C$ content, whereas the irregular curve gives the $G+C$ bias in the third position of the reading frame. The horizontal boxes indicate reading frames starting either with AUG or outside the sequence; in the strip below, each vertical line marks the occurrence of a rare codon. Plots of the complementary strand did not show open reading frames with a high $\mathrm{G}+\mathrm{C}$ bias or infrequent occurrence of rare codons.

DNA extracted from the six $P$. rosea strains and digested with $B a m \mathrm{HI}$ and $P v u I I$ was analysed by Southern blot hybridization using either $\mathrm{pPR} 1$ or $\mathrm{pPR} 2{ }^{32} \mathrm{P}$-labelled DNA as a probe. Only Pbr 1435 and Pbr 1832 gave all the hybridization signals expected for each linear plasmid; the other strains did not hybridize with either plasmid probe (data not shown), ruling out the presence of integrated forms. Since all six $P$. rosea strains both produce and are resistant to the GE2270 antibiotic, these traits are likely to be chromosomally encoded. This is supported by the following observations: (i) recently it has been shown that the $t u f$ gene of $P$. rosea encodes an 


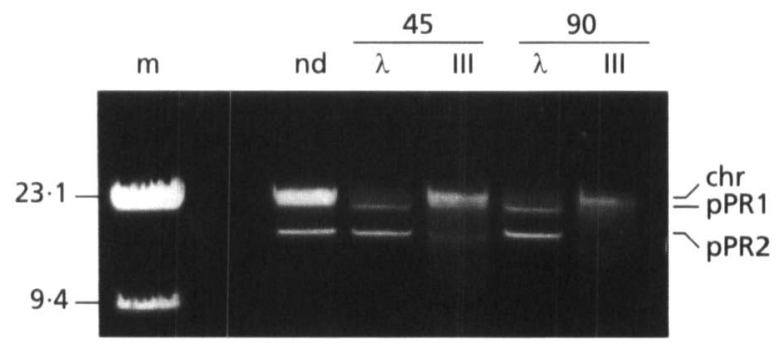

Fig. 3. Exonuclease analysis of $P$. rosea plasmid DNA. Total DNA of $\mathrm{Pbr} 1435$ prepared as described in Methods was treated at $37^{\circ} \mathrm{C}$ with $\lambda$ exonuclease (lanes $\lambda$ ) or exonuclease III (lanes III). Non-digested DNA (lane nd) or DNA digested for 45 and 90 min (lanes labelled 45 and 90 , respectively) was fractionated by $0.5 \%$ agarose gel electrophoresis and visualized under UV light after ethidium bromide staining. Under such conditions the PPR1 DNA migrates at the lower edge of the chromosomal DNA band (chr). Lane $m$ contains molecular mass markers with sizes in $\mathrm{kb}$ indicated on the left.

elongation factor Tu highly resistant in vitro to GE2270 (Sosio et al., 1996); (ii) a chromosomal gene cluster seemingly encoding a biosynthetic pathway for this antibiotic peptide has been cloned and sequenced ( $M$. Sosio \& S. Donadio, unpublished).

Southern blot analysis of plasmid-carrying $P$. rosea DNA also revealed cross-hybridization at high stringency between the third (from the left) SacI fragment of pPR1 and the fourth EcoRI fragment of pPR2. By Southern blot hybridization using subcloned fragments of pPR2 as probes, the region of homology between the two plasmids was restricted to the ApaLI-Sacl fragment of pPR2 shown in Fig. 1 (data not shown).

The DNA fragment encompassing the homologous region was sequenced and the sequence was analysed by the CODONPREFERENCE program (Gribskov et al., 1984), applying the codon usage table compiled for Streptomyces. The analysis revealed the presence of three open reading frames (ORF1, ORF2 and ORF3; Fig. 2), with a high third-position $\mathrm{G}+\mathrm{C}$ bias and infrequent usage of rare codons. Such ORFs are good candidates for coding genes (Bibb et al., 1984). BLAST analysis (Altschul et al., 1990) found similarities between deduced ORF1, ORF2 and ORF3 proteins and the RecF of Mycobacterium tuberculosis (SWISS-PROT Q59586), a guanylyltransferase of Xanthomonas campestris (SWISS-PROT P29956) and several Mut T proteins (Michaels \& Miller, 1992), respectively. ScanProsite search against the PROSITE database (Appel et al., 1994) found the Mut T signature (Koonin, 1993) at aa 169-188 of the ORF3encoded protein. The homologous region of pPR1 and pPR2 might thus code for functions related to recombination and/or DNA repair.

The presence of a common region on two otherwise non-homologous plasmids might suggest the presence of a transposable element. However, we could not detect by sequence analysis diagnostic features of transposons, such as inverted repeats bracketed by direct repeats or ORFs with similarity to known transposases. Also, we did not detect upon Southern blot analysis the presence of additional plasmids that could have arisen by homologous recombination between the two plasmids.

\section{The $5^{\prime}$ ends of pPR1 and PPR2 are protected from $\lambda$ exonuclease digestion}

Many linear plasmids and viruses have a terminal protein linked to their $5^{\prime}$ ends (Salas, 1991; Chen, 1996); their DNA is therefore insensitive to specific $5^{\prime}-3^{\prime}$ DNA exonuclease digestion, even after proteinase $\mathrm{K}$ treatment (Ito, 1978). To determine whether this was true for pPR1 and pPR2, we tested the plasmid DNA for sensitivity to $E$. coli exonuclease III and phage $\lambda$ exonuclease, which degrade dsDNA $3^{\prime}-5^{\prime}$ and $5^{\prime}-3^{\prime}$, respectively. As shown in Fig. 3, DNA exonuclease III degraded both chromosomal and plasmid DNA, whereas $\lambda$ exonuclease degraded chromosomal DNA but not pPR1 and pPR2. These data, together with the observation reported above that in cell lysates not treated with protease the plasmids are lost in the organic phase during DNA extraction, suggest that the $S^{\prime}$ ends of pPR 1 and pPR2 are covalently linked to a terminal protein.

\section{Cloning and sequence analysis of the telomeric regions of $\mathrm{PPR2}$}

Attempts to directly clone restriction fragments containing either end of the plasmid failed, even after proteinase $\mathrm{K}$ or piperidine treatment of the plasmid DNA. To clone the telomeric regions of pPR2 we thus adopted the following strategy: first we cloned the subtelomeric EcoRI fragments and determined the sequence of both left and right telomere-proximal regions. It turned out that such sequences were nearly perfect inverted repeats about 350 nt long (see Fig. 4). Then proteinase-K-treated pPR2 DNA was doubly digested with NheI, which gives a $1.15 \mathrm{~kb}$ fragment containing the left end, and BglII, which gives a $1.55 \mathrm{~kb}$ fragment containing the right end (Fig. 1). The digested DNA was fractionated by agarose gel electrophoresis and the bands corresponding to the left and right ends were excised and purified. The DNA was treated with terminal transferase in the presence of dTTP to tail the 3 ' ends, denatured and replicated with $T a q$ polymerase for ten cycles using poly $(\mathrm{dA})_{35}$ as a primer; PCR was then performed with poly $(\mathrm{dA})_{35}$ and the PLANEND oligonucleotide as primers, the amplified DNA was digested with EcoRI and cloned in EcoRI/SmaI-digested pGEM-3Z. Four clones containing the left end and two containing the right end were obtained and sequenced. All such clones gave identical sequences $310 \mathrm{nt}$ long from the EcoRI site to the run of As at the $5^{\prime}$ end corresponding to the plasmid extremities. To define whether any such A belonged to the pPR $25^{\prime}$ termini, we repeated the above procedure with the right end DNA except that we added a poly (dA) tail at the $3^{\prime}$ end with terminal transferase and amplified the DNA with poly $(\mathrm{dT})_{35}$. Upon cloning and sequencing the amplified DNA, no A was found at the $5^{\prime}$ end of the right pPR2 telomere. 


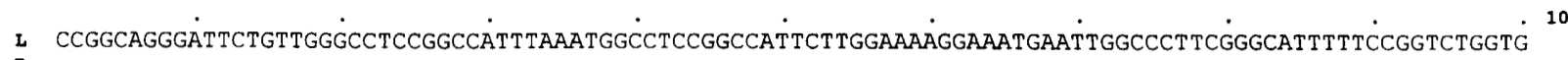

$$
a \underset{a}{a} \frac{1}{a-a} \alpha^{\prime}
$$

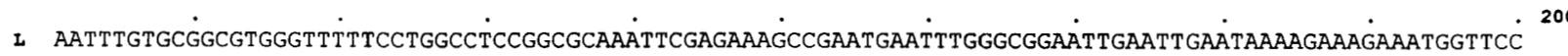

R $\quad C \longrightarrow \ldots \longrightarrow$

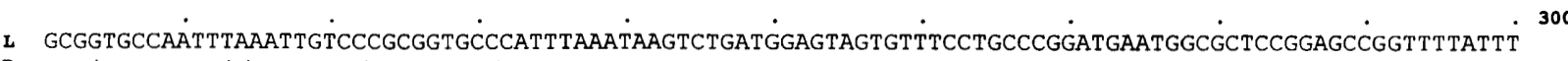

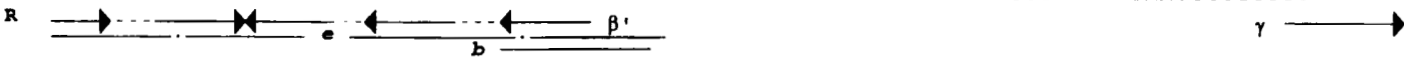

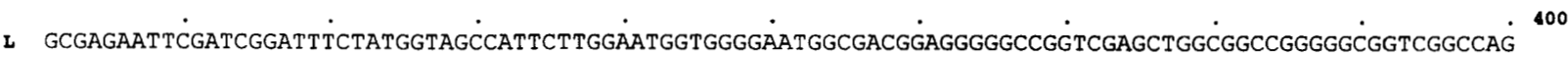
R $d \stackrel{G}{-}$

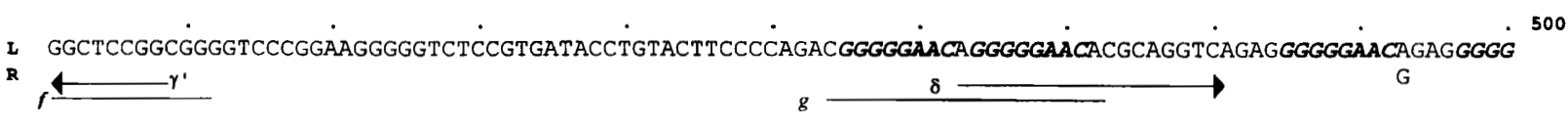

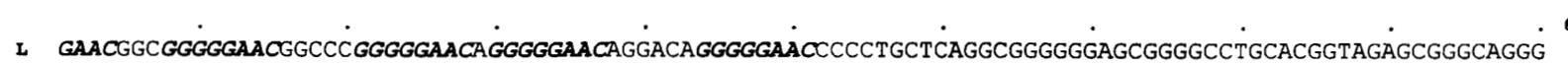

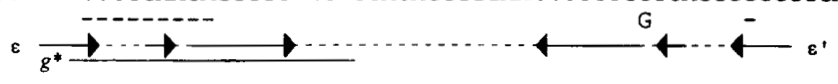

C $\quad C \quad$ GC $T$ T

$\varepsilon \rightarrow \cdots \longrightarrow \longrightarrow \ldots+\ldots$

I CGTTGACCTGCGTGTTCCCCTTTTTTCTGGCGGGAGGGGGAACGGGGTCCCGGGGAGCTGGGAGGGCGCATGGCCGTACAGTCCGGGGAGTCTGTCCCTT I

I GTCCCTAGCGंCGCTGTGAGTGCTGTAAGGCTCCGGCGGACGTGTTGGGGACACGTAGGGGACAGGTCGTÄGGGGACACAGAGCTGAGCTCCTGGTGTCGG 800 R TACACCAGGCCGTCTAACAGTCGTCGGGGCTCTGACCTGCGAAATGCAACCGCGGAACACCGGCCGATGGCGGACCTGGTGAGCTGGGGTAGGTATG... $r^{*} \longrightarrow n^{*} \longrightarrow n^{*}$

Fig. 4. Sequence of the PPR2 telomeric regions. The $5^{\prime}-3^{\prime}$ sequence of the left end, starting from the terminal base, is reported on the upper line marked $L$. Differences observed in the right end sequence are indicated in the lower line (R). Major inverted repeats (arrows labelled with Greek letters) and direct repeats longer than 9 nt (lines labelled with Roman letters) are shown beneath the sequence; an asterisk indicates repeats present only in the left end. The GGGGGAAC repeat is in boldface italics.

The pPR2 telomeric regions (Fig. 4) are composed of two nearly perfect inverted repeats approximately $650 \mathrm{nt}$ long, rich in direct and inverted repeats. The $350 \mathrm{nt}$ long terminal domain has a low $\mathrm{G}+\mathrm{C}$ content $(50 \mathrm{~mol} \%)$, followed by $250 \mathrm{nt}$ rich in $\mathrm{G}+\mathrm{C}(74 \mathrm{~mol} \%)$ and then by DNA with a base composition ( $66 \mathrm{~mol} \% \mathrm{G}+\mathrm{C}$ ) similar to the other sequenced regions of the plasmid. The $\mathrm{G}+\mathrm{C}$-rich region is characterized by multiple direct repetitions of the GGGGGAAC sequence.

Southern blot analysis of restriction-enzyme-digested total $P$. rosea DNA using pPR2 telomeric DNA as a probe gave only hybridization signals corresponding to the pPR2 termini, even at low stringency (data not shown). Thus pPR2 telomeres do not seem to share any significant sequence similarity with those of pPR 1 or any chromosomal sequence of $P$. rosea. In addition, a computer search did not detect any significant sequence similarity to the telomeric regions of other linear DNA molecules.

In conclusion, we have identified two linear plasmids of $P$. rosea that add to the growing list of prokaryotic linear replicons. Both exhibit structural similarities with the Streptomyces linear plasmids and chromosomes in that they appear to have terminal proteins bound to the $5^{\prime}$ ends of their DNA; moreover, the pPR2 telomeres are composed of palindromic sequences rich in direct and inverted repeats. A preliminary analysis of pPR2 replication by two-dimensional gel electrophoresis (data not shown) suggests that pPR2 is not fully replicated starting from the ends but contains an internal origin(s). Although pPR1 and pPR2 share a common central region, they have different telomeres. This suggests that their terminal proteins may also be different.

\section{ACKNOWLEDGEMENTS}

We thank Stefano Donadio and Daniela Ghisotti for comments. This work was supported by Gruppo Lepetit S.p.A.; S.P. was recipient of a Fondazione Adriano Buzzati Traverso fellowship sponsored by Gruppo Lepetit S.p.A.

\section{REFERENCES}

Altschul, S. F., Gish, W., Miller, W., Myers, E. W. \& Lipman, D. J. (1990). Basic local alignment search tool. J Mol Biol 215, 403-410.

Anborgh, P. H. \& Parmeggiani, A. (1991). New antibiotic that acts specifically on the GTP-bound form of elongation factor Tu. EMBO J 10, 779-784.

Appel, R. D., Bairoch, A. \& Hochstrasser, D. F. (1994). A new generation of information retrieval tools for biologists: the example of the ExPASy WWW server. Trends Biochem Sci 19, 258-260. 
Barbour, A. G., Carter, C. J., Bundoc, V. \& Hinnebusch, J. (1996). The nucleotide sequence of a linear plasmid of Borrelia burgdorferi reveals similarities to those of circular plasmids of other prokaryotes. J Bacteriol 178, 6635-6639.

Bibb, M. J., Findlay, P. R. \& Johnson, M. W. (1984). The relationship between base composition and codon usage in bacterial genes and its use for the simple and reliable identification of protein-coding sequences. Gene 30, 157-166.

Casjens, S. \& Huang, W. M. (1993). Linear chromosomal physical and genetic map of Borrelia burgdorferi, the Lyme disease agent. Mol Microbiol 8, 967-980.

Casjens, S., Murphy, M., DeLange, M., Sampson, L., van Vugt, R. \& Huang, W. M. (1997). Telomeres of the linear chromosomes of Lyme disease spirochaetes: nucleotide sequence and possible exchange with linear plasmid telomeres. Mol Microbiol 26, 581-596.

Chang, P.-C. \& Cohen, S. (1994). Bidirectional replication from an internal origin in a linear Streptomyces plasmid. Science 265, 952-954.

Chang, P.-C., Kim, E.-S. \& Cohen, S. (1996). Streptomyces linear plasmids that contain a phage-like, centrally located, replication origin. Mol Microbiol 22, 789-800.

Chen, C. W. (1996). Complications and implications of linear bacterial chromosomes. Trends Genet 12, 192-196.

Chen, C. W., Yu, T.-W., Lin, Y.-S., Lieser, H. M. \& Hopwood, D. A. (1993). The conjugative plasmid SLP2 of Streptomyces lividans is a $50 \mathrm{~kb}$ linear molecule. Mol Microbiol 7, 925-932.

Crespi, M., Messens, E., Caplan, A. B., Van Montagu, M. \& Desomer, J. (1992). Fasciation induction by the phytopathogen $R$ hodococcus fascians depends upon a linear plasmid encoding a cytokine synthase gene. EMBO J 11, 795-804.

Davies, J. (1994). New pathogens and old resistance genes. Microbiologia 10, 9-12.

Devereux, J., Haeberli, P. \& Smithies, O. (1984). A comprehensive set of sequence analysis programs for the VAX. Nucleic Acids Res 12, 387-395.

Fishman, S. E. \& Hershberger, C. L. (1983). Amplified DNA in Streptomyces fradiae. J Bacteriol 155, 459-466.

Fraser, C. M., Casjens, S., Huang, W. M. \& 35 other authors (1997). Genomic sequence of a Lyme disease spirochaete, Borrelia burgdorferi. Nature 390, 580-586.

Goodfellow, M. (1992). The family Streptosporangiaceae. In The Prokaryotes, 2nd edn, pp. 1115-1138. Edited by A. Balows, H. G. Trüper, M. Dworkin, W. Harder \& K.-H. Schleifer. New York: Springer.

Gribskov, M., Devereux, J. \& Burgess, R. R. (1984). The codon preference plot: graphic analysis of protein coding sequences and prediction of gene expression. Nucleic Acids Res 12, 539-549.

Hanahan, D. (1983). Studies on transformation of Escherichia coli with plasmids. $J$ Mol Biol 4, 557-580.

Hinnebusch, J. \& Barbour, G. (1991). Linear plasmids of Borrelia burgdorferi have a telomeric structure and sequence similar to those of a eukaryotic virus. J Bacteriol 173, 7233-7239.

Hinnebusch, J. \& Tilly, K. (1993). Linear plasmids and chromosomes in bacteria. Mol Microbiol 710, 917-922.

Hintermann, G., Crameri, R., Kieser, T. \& Huetter, R. (1981). Restriction analysis of the Streptomyces glaucescens genome by agarose gel electrophoresis. Arch Mikrobiol 130, 218-222.

Hirochika, H., Nakamura, K. \& Sakaguchi, K. (1984). A linear DNA plasmid from Streptomyces rochei with an inverted terminal repetition of 614 base pairs. EMBO J 3, 761-766.
Ito, J. (1978). Bacteriophage $\Phi 29$ terminal protein : its association with the $5^{\prime}$ termini of the $\Phi 29$ genome. J Virol 28, 895-904.

Kalkus, J., Reh, M. \& Schlegel, H. G. (1990). Hydrogen autotrophy of Nocardia opaca strains is encoded by linear megaplasmids. J Gen Microbiol 136, 1145-1151.

Kalkus, J., Dörrie, C., Fischer, D., Reh, M. \& Schlegel, H. G. (1993). The giant linear plasmid pHG207 from R hodococcus sp. encoding hydrogen autotrophy: characterization of the plasmid and its termini. J Gen Microbiol 139, 2055-2065.

Kinashi, H., Shimaji, M. \& Sakai, A. (1987). Giant linear plasmids in Streptomyces which code for antibiotic synthesis genes. Nature $328,454-456$.

Kinashi, H., Shimaji-Murayama, M. \& Hanafusa, T. (1991). Nucleotide sequence analysis of the unusually long terminal inverted repeats of a giant linear plasmid, SCP1. Plasmid 26, 123-130.

Koonin, E. V. (1993). A highly conserved sequence motif defining the family of MutT-related proteins from eubacteria, eukaryotes and viruses. Nucleic Acids Res 21, 4847.

Leblond, P., Fisher, G., Francois-Xavier, F., Berger, F., Guerineau, M. \& Decaris, B. (1996). The unstable region of Streptomyces ambofaciens includes $210 \mathrm{~kb}$ terminal inverted repeats flanking the extremities of the linear chromosomal DNA. Mol Microbiol 19, 261-271.

Lezhava, A. L., Mizukami, T., Kajitani, T., Kameoka, D., Redenbach, M., Shinkawa, H., Nimi, O. \& Kinashi, H. (1995). Physical map of the linear chromosome of Streptomyces griseus. $J$ Bacteriol 177, 6492-6498.

Lin, Y.-S., Kieser, H. M., Hopwood, D. A. \& Chen, C. W. (1993). The chromosomal DNA of Streptomyces lividans 66 is linear. Mol Microbiol 10, 923-933.

tobocka, M. G., Svarchevsky, A. N., Rybchin, V. N. \& Yarmolinsky, M. B. (1996). Characterization of the primary immunity region of the Escherichia coli linear plasmid prophage N15. J Bacteriol 178, 2902-2910.

Malinin, A. J., Vostrov, A. A., Rybchin, V. N. \& Svarchevsky, A. N. (1992). Structure of the linear plasmid N15 ends. Mol Genet 5-6, 22-25 (in Russian).

Maniatis, T., Fritsch, E. F. \& Sambrook, J. (1982). Molecular Cloning : a Laboratory Manual. Cold Spring Harbor, NY: Cold Spring Harbor Laboratory.

Michaels, M. L. \& Miller, J. H. (1992). The GO system protects organisms from the mutagenic effect of the spontaneous lesion 8-hydroxyguanine (7,8-dihydro-8-oxoguanine). J Bacteriol 174, $6321-6325$

Sakaguchi, K. (1990). Invertrons, a class of structurally and functionally related genetic elements that include linear DNA plasmids, transposable elements and genomes of adeno-type viruses. Microbiol Rev 54, 66-74.

Salas, M. (1991). Protein-priming of DNA replication. Annu Rev Biochem 60, 39-71.

Sanger, F., Nicklen, S. \& Coulson, A. R. (1977). DNA sequencing with chain-terminating inhibitors. Proc Natl Acad Sci USA 74, 5463-5467.

Selva, E., Beretta, G., Montanini, N. \& 9 other authors (1991). Antibiotic GE 2270A: a novel inhibitor of bacterial protein synthesis. I. Isolation and characterization. J Antibiot 44, 693-701.

Sosio, M., Amati, G., Cappellano, C., Sarubbi, E., Monti, F. \& Donadio, S. (1996). An elongation factor $\mathrm{Tu}$ (EF-Tu) resistant to the EF-Tu inhibitor GE 2270 in the producing organism Planobispora rosea. Mol Microbiol 22, 43-51. 
Svarchevsky, A. N. \& Rybchin, V. N. (1984). Characterization of plasmid properties of bacteriophage N15. Mol Gen 5, 34-39 (in Russian).

Tavecchia, P., Gentili, P., Kurz, M., Sottani, C., Bonfichi, R., Selva, E., Lociuro, S., Restelli, E. \& Ciabatti, R. (1995). Degradation studies of antibiotic MDL 62,879 (GE $2270 \mathrm{~A}$ ) and revision of the structure. Tetrabedron 51, 4867-4890.

Wu, X. \& Roy, K. L. (1993). Complete nucleotide sequence of a linear plasmid from Streptomyces clavuligerus and characterization of its RNA transcripts. J Bacteriol 175, 37-52.

Yanisch-Perron, C., Vieira, J. \& Messing, J. (1985). Improved M13 phage cloning vectors and host strains: nucleotide sequences of the M13mp18 and pUC19 vectors. Gene 33, 103-119.

Received 19 February 1998; revised 28 May 1998; accepted 2 June 1998. 